\title{
Malaria and hypertension. Another co-evolutionary adaptation?
}

\author{
Julio Gallego-Delgado and Ana Rodriguez* \\ *Correspondence: ana.rodriguez@nyumc.org \\ Edited by: \\ Samuel C. Wassmer, New York University School of Medicine, USA \\ Reviewed by: \\ Mauricio Martins Rodrigues, Federal University of São Paulo, Brazil \\ Andrea L. Conroy, University of Toronto, Canada
}

Division of Parasitology, Department of Microbiology, New York University School of Medicine, New York, NY, USA

Keywords: malaria, plasmodium, hypertension, angiotensin II, polymorphism, ethnicity, evolutionary adaptation

Arterial hypertension is a complex multifactorial disease and a global public health concern. It is responsible for at least $45 \%$ of deaths due to heart disease and $51 \%$ of deaths due to stroke, adding up the tremendous number of 9.4 million deaths every year (Lim et al., 2012; World Health Organization, 2013). The renin-angiotensin-aldosterone system (RAAS) is one of the most important regulatory systems of blood volume, arterial pressure and cardiovascular homeostasis. Angiotensin II (Ang II) is the principal effector hormone of the RAAS in vascular biology, mediating effects via two main receptors: Angiotensin receptor type 1 (AT1) and type 2 (AT2) (Callera et al., 2007). When Ang II binds to AT1 on vascular smooth muscle cells, it mobilizes intracellular $\mathrm{Ca}^{2+}$, leading to cellular contraction. Sustained cellular contraction increases peripheral vascular resistance, resulting in high blood pressure (Touyz and Schiffrin, 2000).

Among others, genetic factors are closely related with the development of hypertension. People with African American and South Asian genetic background have higher prevalence of hypertension compared to Caucasians, independently of their socioeconomic status (Cappuccio, 1997; Sampson et al., 2014). These differences in the ethnic background can increase the prevalence of hypertension by 2 fold until the age of 55 , when the differences decline, presumably because of the interfering effect of age-related factors (Wolz et al., 2000). Several polymorphisms have been associated with higher prevalence of arterial hypertension; there are 2 polymorphisms in the Angiotensin Converting Enzyme (ACE) and Angiotensin Converting Enzyme 2 (ACE2) that lead to elevate circulating Ang II levels (Giner et al., 2000; Di Pasquale et al., 2004; Fan et al., 2007). Interestingly, these same genetic variations (the "D" allele of ACE I/D polymorphism and the ACE2 $\mathrm{C} \rightarrow \mathrm{T}$ substitution) have been associated with a lower incidence of cerebral malaria $(\mathrm{CM})$ in Indian adults, although the later one only in women (Dhangadamajhi et al., 2010).

Malaria is still a major public health problem world wide, causing approximately 600,000 deaths, mostly among African children (World Health Organization, 2012a). A high proportion of these deaths are caused by CM, a syndrome characterized by impaired consciousness, generalized convulsions, coma and neurological sequelae (Idro et al., 2005). CM is caused by the interaction between Plasmodium falciparum infected erythrocytes and host brain endothelial cells. Parasite proteins that are expressed on the surface of infected erythrocytes (PfEMP1), interact with host endothelial cell receptors (Protein C receptor, ICAM1; Newbold et al., 1997; Turner et al., 2013) leading to their sequestration within the brain microcirculation. Disruption of the blood-brain barrier is observed producing the characteristic petechiae and ring hemorrhages found on the brain of dead patients with CM (Rasti et al., 2004).

Although it is still not well-established that Ang II has beneficial effects on malaria and particularly on $\mathrm{CM}$, different lines of evidence suggest a possible 'protective' effect that could be mediated by different, non-exclusive mechanisms that could affect parasite development and/or host susceptibility to Plasmodium-induced pathology.

Recent reports have shown that angiotensin peptides can induce impairment of the erythrocytic cycle of Plasmodium, reducing the parasite growth in vitro (Maciel et al., 2008; Saraiva et al., 2011). Since the development of CM depends on the initial levels of parasitemia in mice (Amani et al., 1998) and possibly in humans (Bejon et al., 2005), this could be a potential explanation for Ang II protection from CM. Our unpublished results using mice infected with Plasmodium berghei seem to confirm that the elevation of Ang II levels results in modestly decreased parasitemias in this animal model.

It is possible that Ang II could modulate malaria severity through additional mechanisms, specially, since the inhibitory effect observed in parasite growth is modest (Maciel et al., 2008; Saraiva et al., 2011). Sodium conservation could provide an alternative explanation to the protective effect of the polymorphisms associated with higher levels of Ang II. In this case, Ang II could be acting to counterbalance hyponatremia by stimulating the secretion of aldosterone from the adrenal cortex, the major regulator of $\mathrm{Na}^{+}$reabsorption. Hyponatremia (serum sodium $<135 \mathrm{mmol} / \mathrm{L}$ ) is frequent in malaria patients and correlates with disease severity in imported malaria (van Wolfswinkel et al., 2010). However, other studies have shown that circulating $\mathrm{Na}^{+}$ 
levels have no predictor value for the outcome of malaria (Phillips et al., 2009) and are not associated with increased mortality (Hanson et al., 2009). Further investigations are necessary to elucidate the role of serum $\mathrm{Na}^{+}$levels in the outcome of severe malaria and its possible relation with polymorphisms of the RAAS.

A protective effect of Ang II against CM may also be mediated by effects on the host vascular endothelial cells. Ang II exerts its vasoconstriction effect through the AT1 receptor on vascular smooth muscle cells (de Gasparo et al., 1990). However, since the $\mathrm{BBB}$ is impermeable to Ang II and other RAAS peptides, circulating Ang II does not reach underlying vascular muscular cells and vascular pressure in the brain is locally regulated by Ang II produced within the brain parenchyma (Bader, 2010). In the context of CM, higher levels of circulating Ang II would not increase vasoconstriction in the brain, but could affect endothelial cells that form the BBB and express both, AT1 and AT2 receptors. Using monolayers of human brain microvascular endothelial cells, we have observed that incubation with erythrocytes infected with Plasmodium falciparum promotes the disruption of interendothelial cell junctions between these cells. Activation of AT2 or inhibition of AT1 receptor preserves the integrity of interendothelial cell junctions after incubation with $P$. falciparum in vitro and protect against experimental CM in mice (Gallego-Delgado et al., 2013). This could be key in the association of Ang II with lower development of CM since AT2 receptor stimulation has protective effects on brain injury (McCarthy et al., 2009; Habashi et al., 2011) and inhibits vascular endothelial cells migration (Falcon et al., 2005). Gene expression analysis comparing CM-susceptible mice vs. CMresistant mice also showed higher expression levels of the AT2 receptor gene in CM-resistant mice compared to susceptible ones (Delahaye et al., 2007). Also, activation of AT2 receptor results in increased production of nitric oxide by endothelial Nitric Oxide Synthase (eNOS) in endothelial cells (Yayama and Okamoto, 2008), which could be protective against cerebral malaria since low nitric oxide bioavailability may exacerbate endothelial dysfunction and contributes to the pathogenesis of severe malaria (Gramaglia et al., 2006; Miller et al., 2013). Interestingly, polymorphisms in eNOS that are responsible for increased expression and nitric oxide production have been associated with mild malaria (Dhangadamajhi et al., 2009, 2010).

Finally, it has also been proposed that the effects of Ang II in malaria severity could be mediated by immune mechanisms, since activation of AT1 by Ang II is a pro-inflammatory stimulus (Benigni et al., 2010). In this case, elevated levels of Ang II would result in higher inflammation that would contribute to the activation of endothelial cells and would be detrimental for the outcome of severe malaria. Treatment of Plasmodium-infected mice with losartan, an inhibitor of AT1, and captopril, an inhibitor of ACE that reduces the levels of Ang II, inhibit T cell activation induced by infection (Silva-Filho et al., 2013). Treatment with losartan, which inhibits the signaling of Ang II through AT1, while potentiating the effects mediated by AT2, would result in decreased endothelial cell migration and lower disruption of interendothelial cell junctions, in addition to anti-inflammatory systemic effects (Marchesi et al., 2008) and would align with the hypothesis of a beneficial effect of Ang II in malaria severity. However, the effects of captopril, reducing Ang II, decreasing parasitemia and protecting against experimental CM (SilvaFilho et al., 2013), apparently do not agree with the hypothesis that increased Ang II provides protection against severe malaria. Further experiments in vivo are necessary to elucidate the signaling pathways, AT1 vs. AT2, mediating the observed effects on malaria severity of different concentrations of systemic Ang II in parasite development and generation of CM.

Humans have been infected by P. falciparum for over 50,000 years (the estimated date for the out-of-Africa migration) and have co-evolved during this time (Tanabe et al., 2010). Different human polymorphisms, such as those causing thalassemia or sickle cell anemia, have been associated to this natural selection process. Although there is not sufficient evidence available to demonstrate it, the association of polymorphisms of the ACE and protection from severe malaria may also be the result of a natural selection process. This apparent contradiction would be explained if higher levels of Ang II at early ages protect from CM. In this case, those polymorphisms would have a higher transmission ratio, despite their deleterious effects during adulthood, as observed in people with African American genetic background (Sampson et al., 2014).

While hypertension has been traditionally considered a disease of western countries, in the latest years it has become obvious that hypertension is coming to epidemic levels in Africa, even presenting higher prevalence than in wealthier countries, possibly because of the higher levels of circulating Ang II found in people with African genetic background (Addo et al., 2007; Lloyd-Sherlock et al., 2014). As a consequence, a significant number of African natives are currently taking antihypertensive medication, and this number is expected to increase exponentially in the coming years (Lloyd-Sherlock et al., 2014). If further investigations demonstrate that Ang II levels influence the development of CM, hypertension treatment in malaria endemic areas should take this effect into consideration.

Finding polymorphisms associated to hypertension in Sub-Saharan Africa could help to select the adequate antihypertensive treatment in these highly vulnerable populations (Mokwe et al., 2004; Peck et al., 2013). The fact that differences in the ethnic background correlate with differences in the response to antihypertensive drugs suggests that the genetic background could be an essential factor to consider when it comes to choose the better antihypertensive regimen to control blood pressure (Gupta, 2010; Gupta et al., 2010).

Another population possibly affected by the influence of anti-hypertensive medication on malaria severity would be travelers from western countries going to malaria endemic areas. Nonimmune malaria patients, such as travelers, are more susceptible to succumb to CM and develop neurological sequelae (Alrajhi et al., 1999; Roze et al., 2001). But not all nonimmune travelers have the same odds to develop malaria complications. In a 16year period clinical study of natives from malaria-nonendemic countries infected with malaria, Phillips et al. showed that the 
odds of severe malaria were 8-fold lower among black than other ethnic groups suggesting genetic factors to contribute to the outcome of the disease (Phillips et al., 2009). WHO estimates that over 100 countries with risk of malaria transmission receive 125 million travelers every year and reports 10,000 cases of malaria among them (World Health Organization, $2012 b$ ). Given that $\sim 20 \%$ of the adult population in western countries is hypertensive, a significant number of those travelers would be taking anti-hypertensive medication while in malaria endemic territories. A first line therapy for hypertension treatment are the Angiotensin converting enzyme inhibitors (ACEi) that inhibit the production of Ang II from angiotensin I. However, in malaria endemic areas, reducing the levels of systemic Ang II could be reducing the chances of a good outcome in the case of a malaria infection. Alternative anti-hypertensive drugs, that do not target ACE, for hypertensive travelers would be decreasing the chances of developing $\mathrm{CM}$ in case of acquiring malaria.

Overall, there are evidences suggesting that RAAS, and more specifically Ang II, may influence the severity of malaria. Although the available data are still very limited, it is conceivable that Ang II could be protecting the integrity of the $\mathrm{BBB}$ in the setting of $\mathrm{CM}$ and giving a survival advantage to those that carry polymorphisms resulting in higher levels of systemic Ang II. Mechanistic studies to determine the role of Ang II in inflammation, endothelial cell barrier formation, sodium conservation and parasite growth in the context of malaria are needed before any solid conclusions can be reached. It is possible that polymorphisms acquired because of their protective effect against malaria have turned out to contribute together with the western societies life-style to the worldwide epidemic proportions of hypertension. However, the available data in this sense are still scarce and additional genetic studies are necessary in other malaria endemic regions (specially in sub-Saharan Africa) to determine whether malaria could have been a driving evolutionary force for RAAS polymorphisms, and therefore for hypertension.

\section{ACKNOWLEDGMENT}

Funding was provided by FECYT (mobility program), Ministry of Education of Spain for Julio Gallego-Delgado.

\section{REFERENCES}

Addo, J., Smeeth, L., and Leon, D. A. (2007). Hypertension in sub-saharan Africa: a systematic review. Hypertension 50, 1012-1018. doi: 10.1161/HYPERTENSIONAHA.107.093336

Alrajhi, A. A., Rahim, I., Akood, M., and Hazmi, M. (1999). Chloroquine-resistant Plasmodium falciparum cerebral malaria in a chloroquinesusceptible area. J. Infect. Dis. 180, 1738-1741. doi: $10.1086 / 315083$

Amani, V., Boubou, M. I., Pied, S., Marussig, M., Walliker, D., Mazier, D., et al. (1998). Cloned lines of Plasmodium berghei ANKA differ in their abilities to induce experimental cerebral malaria. Infect. Immun. 66, 4093-4099.

Bader, M. (2010). Tissue renin-angiotensinaldosterone systems: targets for pharmacological therapy. Аnпu. Rev. Pharmacol. Toxicol. 50, 439-465. doi: 10.1146/annurev.pharmtox.010909. 105610

Bejon, P., Andrews, L., Andersen, R. F., Dunachie, S., Webster, D., Walther, M., et al. (2005). Calculation of liver-to-blood inocula, parasite growth rates, and preerythrocytic vaccine efficacy, from serial quantitative polymerase chain reaction studies of volunteers challenged with malaria sporozoites. J. Infect. Dis. 191, 619-626. doi: 10.1086/427243

Benigni, A., Cassis, P., and Remuzzi, G. (2010). Angiotensin II revisited: new roles in inflammation, immunology and aging. EMBO Mol. Med. 2, 247-257. doi: 10.1002/emmm.201000080

Callera, G., Tostes, R., Savoia, C., Muscara, M. N., and Touyz, R. M. (2007). Vasoactive peptides in cardiovascular (patho)physiology. Expert Rev. Cardiovasc. Ther. 5, 531-552. doi: 10.1586/ 14779072.5.3.531

Cappuccio, F. P. (1997). Ethnicity and cardiovascular risk: variations in people of African ancestry and South Asian origin. J. Hum. Hypertens. 11, 571-576.

de Gasparo, M., Whitebread, S., Mele, M., Motani, A. S., Whitcombe, P. J., Ramjoue, H. P., et al. (1990). Biochemical characterization of two angiotensin II receptor subtypes in the rat. J. Cardiovasc. Pharmacol. (16 Suppl. 4), S31-S35.

Delahaye, N. F., Coltel, N., Puthier, D., Barbier, M., Benech, P., Joly, F., et al. (2007). Gene expression analysis reveals early changes in several molecular pathways in cerebral malaria-susceptible mice versus cerebral malaria-resistant mice. BMC Genomics 8:452. doi: 10.1186/1471-2164-8-452

Dhangadamajhi, G., Mohapatra, B. N., Kar, S. K., and Ranjit, M. (2009). Endothelial nitric oxide synthase gene polymorphisms and Plasmodium falciparum infection in Indian adults. Infect. Immun. 77, 2943-2947. doi: 10.1128/IAI.00083-09

Dhangadamajhi, G., Mohapatra, B. N., Kar, S. K., and Ranjit, M. (2010). Gene polymorphisms in angiotensin I converting enzyme (ACE I/D) and angiotensin II converting enzyme (ACE2 $\mathrm{C}->\mathrm{T}$ ) protect against cerebral malaria in Indian adults. Infect. Genet. Evol. 10, 337-341. doi: 10.1016/j.meegid.2010.01.009
Di Pasquale, P., Cannizzaro, S., and Paterna, S. (2004). Does angiotensin-converting enzyme gene polymorphism affect blood pressure? Findings after 6 years of follow-up in healthy subjects. Eur. J. Heart Fail. 6, 11-16. doi: 10.1016/j.ejheart.2003.07.009

Falcon, B. L., Veerasingham, S. J., Sumners, C., and Raizada, M. K. (2005). Angiotensin II type 2 receptor-mediated gene expression profiling in human coronary artery endothelial cells. Hypertension 45, 692-697. doi: 10.1161/01.HYP. 0000154254.89733 .29

Fan, X., Wang, Y., Sun, K., Zhang, W., Yang, X., Wang, S., et al. (2007). Polymorphisms of ACE2 gene are associated with essential hypertension and antihypertensive effects of Captopril in women. Clin. Pharmacol. Ther. 82, 187-196. doi: 10.1038/sj.clpt.6100214

Gallego-Delgado, J. T. M., Alique, M., Wassmer, S., Ruiz-Ortega, M., and Rodriguez, A. (eds.). (2013). "Abstract book," in ASTMH 62nd Annual Meeting (Washington, DC: The American Journal of Tropical Medicine and Hygiene).

Giner, V., Poch, E., Bragulat, E., Oriola, J., Gonzalez, D., Coca, A., et al. (2000). Renin-angiotensin system genetic polymorphisms and salt sensitivity in essential hypertension. Hypertension 35(1 Pt 2), 512-517. doi: 10.1161/01.HYP.35.1.512

Gramaglia, I., Sobolewski, P., Meays, D., Contreras, R., Nolan, J. P., Frangos, J. A., et al. (2006). Low nitric oxide bioavailability contributes to the genesis of experimental cerebral malaria. Nat. Med. 12, 1417-1422. doi: 10.1038/nm1499

Gupta, A. K. (2010). Racial differences in response to antihypertensive therapy: does one size fits all? Int. J. Prev. Med. 1, 217-219.

Gupta, A. K., Poulter, N. R., Dobson, J., Eldridge, S., Cappuccio, F. P., Caulfield, M., et al. (2010). Ethnic differences in blood pressure response to first and second-line antihypertensive therapies in patients randomized in the ASCOT Trial. Am. J. Hypertens. 23, 1023-1030. doi: 10.1038/ajh.2010.105

Habashi, J. P., Doyle, J. J., Holm, T. M., Aziz, H., Schoenhoff, F., Bedja, D., et al. (2011). Angiotensin II type 2 receptor signaling attenuates aortic aneurysm in mice through ERK antagonism. Science 332, 361-365. doi: 10.1126/science. 1192152

Hanson, J., Hossain, A., Charunwatthana, P., Hassan, M. U., Davis, T. M., Lam, S. W., et al. (2009). Hyponatremia in severe malaria: evidence for an appropriate anti-diuretic hormone response to hypovolemia. Am. J. Trop. Med. Hyg. 80, 141-145.

Idro, R., Jenkins, N. E., and Newton, C. R. (2005). Pathogenesis, clinical features, and neurological outcome of cerebral malaria. Lancet Neurol. 4, 827-840. doi: 10.1016/S1474-4422(05)70247-7

Lim, S. S., Vos, T., Flaxman, A. D., Danaei, G., Shibuya, K., Adair-Rohani, H., et al. (2012). A comparative risk assessment of burden of disease and injury attributable to 67 risk factors and risk factor clusters in 21 regions, 1990-2010: a systematic analysis for the Global Burden of Disease Study 2010. Lancet 380, 2224-2260. doi: 10.1016/S01406736(12)61766-8

Lloyd-Sherlock, P., Ebrahim, S., and Grosskurth, H. (2014). Is hypertension the new HIV epidemic? Int. J. Epidemiol. 43, 8-10. doi: 10.1093/ije/dyu019 Maciel, C., de Oliveira Junior, V. X., Fazio, M. A., Nacif-Pimenta, R., Miranda, A., Pimenta, 
P. F., et al. (2008). Anti-plasmodium activity of angiotensin II and related synthetic peptides. PLoS ONE 3:e3296. doi: 10.1371/journal.pone.0003296

Marchesi, C., Paradis, P., and Schiffrin, E. L. (2008). Role of the renin-angiotensin system in vascular inflammation. Trends Pharmacol. Sci. 29, 367-374. doi: 10.1016/j.tips.2008.05.003

McCarthy, C. A., Vinh, A., Callaway, J. K., and Widdop, R. E. (2009). Angiotensin AT2 receptor stimulation causes neuroprotection in a conscious rat model of stroke. Stroke 40, 1482-1489. doi: 10.1161/STROKEAHA.108.531509

Miller, L. H., Ackerman, H. C., Su, X. Z., and Wellems, T. E. (2013). Malaria biology and disease pathogenesis: insights for new treatments. Nat. Med. 19, 156-167. doi: 10.1038/nm.3073

Mokwe, E., Ohmit, S. E., Nasser, S. A., Shafi, T., Saunders, E., Crook, E., et al. (2004). Determinants of blood pressure response to quinapril in black and white hypertensive patients: the Quinapril Titration Interval Management Evaluation trial. Hypertension 43, 1202-1207. doi: 10.1161/01.HYP.0000127924. 67353.86

Newbold, C., Warn, P., Black, G., Berendt, A., Craig, A., Snow, B., et al. (1997). Receptor-specific adhesion and clinical disease in Plasmodium falciparum. Am. J. Trop. Med. Hyg. 57, 389-398.

Peck, R. N., Smart, L. R., Beier, R., Liwa, A. C., Grosskurth, H., Fitzgerald, D. W., et al. (2013). Difference in blood pressure response to ACEInhibitor monotherapy between black and white adults with arterial hypertension: a meta-analysis of 13 clinical trials. BMC Nephrol. 14:201. doi: 10.1186/1471-2369-14-201

Phillips, A., Bassett, P., Zeki, S., Newman, S., and Pasvol, G. (2009). Risk factors for severe disease in adults with falciparum malaria. Clin. Infect. Dis. 48, 871-878. doi: 10.1086/597258

Rasti, N., Wahlgren, M., and Chen, Q. (2004). Molecular aspects of malaria pathogenesis. FEMS Immunol. Med. Microbiol. 41, 9-26. doi: 10.1016/j.femsim.2004.01.010

Roze, E., Thiebaut, M. M., Mazevet, D., Bricaire, F., Danis, M., Deseilligny, C. P., et al. (2001). Neurologic sequelae after severe falciparum malaria in adult travelers. Eur. Neurol. 46, 192-197. doi: 10.1159/000050803

Sampson, U. K., Edwards, T. L., Jahangir, E., Munro, H., Wariboko, M., Wassef, M. G., et al. (2014). Factors associated with the prevalence of hypertension in the southeastern United States: insights from 69,211 blacks and whites in the Southern Community Cohort Study. Circ. Cardiovasc. Qual. Outcomes 7, 33-54. doi: 10.1161/CIRCOUTCOMES.113.000155

Saraiva, V. B., de Souza Silva, L., Ferreira-DaSilva, C. T., da Silva-Filho, J. L., Teixeira-Ferreira, A., Perales, J., et al. (2011). Impairment of the Plasmodium falciparum erythrocytic cycle induced by angiotensin peptides. PLOS ONE 6:e17174. doi: 10.1371/journal.pone.0017174

Silva-Filho, J. L., Souza, M. C., Ferreira-Dasilva, C. T., Silva, L. S., Costa, M. F., Padua, T. A., et al. (2013). Angiotensin II is a new component involved in splenic $\mathrm{T}$ lymphocyte responses during Plasmodium berghei ANKA infection. PLoS ONE 8:e62999. doi: 10.1371/journal.pone.00 62999

Tanabe, K., Mita, T., Jombart, T., Eriksson, A., Horibe, S., Palacpac, N., et al. (2010). Plasmodium falciparum accompanied the human expansion out of Africa. Curr. Biol. 20, 1283-1289. doi: 10.1016/j.cub.2010.05.053

Touyz, R. M., and Schiffrin, E. L. (2000). Signal transduction mechanisms mediating the physiological and pathophysiological actions of angiotensin II in vascular smooth muscle cells. Pharmacol. Rev. 52, 639-672.

Turner, L., Lavstsen, T., Berger, S. S., Wang, C. W., Petersen, J. E., Avril, M., et al. (2013). Severe malaria is associated with parasite binding to endothelial protein C receptor. Nature 498, 502-205. doi: 10.1038/nature12216

van Wolfswinkel, M. E., Hesselink, D. A., Zietse, R., Hoorn, E. J., and van Genderen, P. J. (2010). Hyponatraemia in imported malaria is common and associated with disease severity. Malar. J. 9, 140. doi: 10.1186/1475-2875-9-140

Wolz, M., Cutler, J., Roccella, E. J., Rohde, F., Thom, T., and Burt, V. (2000). Statement from the National High Blood Pressure
Education Program: prevalence of hypertension. Am. J. Hypertens. 13(1 Pt 1), 103-104. doi: 10.1016/S0895-7061(99)00241-1

World Health Organization. (2012a). World Malaria Report 2012. Vol. xxxiv. Geneva: World Health Organization.

World Health Organization. (2012b). International Travel and Health: Situation as on 1 January 2012. Vol. xi. Geneva: World Health Organization.

World Health Organization. (2013). A Global Brief on Hypertension. Geneva: World Health Organization. Available online at: http://www. who.int/cardiovascular_diseases/publications/glob al_brief_hypertension/en/

Yayama, K., and Okamoto, H. (2008). Angiotensin II-induced vasodilation via type 2 receptor: role of bradykinin and nitric oxide. Int Immunopharmacol. 8, 312-318. doi: 10.1016/ j.intimp.2007.06.012

Conflict of Interest Statement: The Guest Associate Editor Samuel C. Wassmer declares that, despite being affiliated to the same institution as the authors, the review process was handled objectively and no conflict of interest exists. The authors declare that the research was conducted in the absence of any commercial or financial relationships that could be construed as a potential conflict of interest.

Received: 28 May 2014; accepted: 16 August 2014; published online: 03 September 2014.

Citation: Gallego-Delgado J and Rodriguez A (2014) Malaria and hypertension. Another co-evolutionary adaptation? Front. Cell. Infect. Microbiol. 4:121. doi: $10.3389 / f_{\text {cimb. }} 2014.00121$

This article was submitted to the journal Frontiers in Cellular and Infection Microbiology.

Copyright (c) 2014 Gallego-Delgado and Rodriguez. This is an open-access article distributed under the terms of the Creative Commons Attribution License (CC BY). The use, distribution or reproduction in other forums is permitted, provided the original author(s) or licensor are credited and that the original publication in this journal is cited, in accordance with accepted academic practice. No use, distribution or reproduction is permitted which does not comply with these terms. 